\title{
A Case of Cellular Fibrous Histiocytoma on the Right Elbow with Repeated Relapse within a Short Period
}

\author{
Kanako Tsunoda ${ }^{a}$ Hiroki Oikawa $^{\mathrm{b}}$ Fumihiko Maeda $^{\mathrm{a}}$ \\ Kazuhiro Takahashi ${ }^{a}$ Toshihide Akasaka $^{a}$ \\ Departments of ${ }^{\mathrm{a}}$ Dermatology and ${ }^{\mathrm{b}}$ Pathology, School of Medicine, Iwate Medical \\ University, Morioka, Japan
}

\section{Key Words}

Cellular fibrous histiocytoma - Dermatofibrosarcoma protuberans · Factor XIIIa · CD34 ·

CD163 · CD44

\begin{abstract}
Cellular fibrous histiocytoma, a variant of fibrous histiocytoma, is a designation used for lesions showing increased cellularity with a fascicular growth pattern and frequent extension into the subcutis. Here we describe a case of cellular fibrous histiocytoma showing repeated recurrence in a 36-year-old woman who initially presented with a 2-cm cutaneous tumor on her right elbow. Histopathologically, the first resected specimen demonstrated irregularly arranged collagen fibers mixed with scattered proliferating plump to spindle-shaped fibrohistiocytes. However, examination of the resected specimens obtained after recurrence showed that the cellularity had increased, the spindle-shaped cells showing monomorphic proliferation with a fascicular and storiform growth pattern extending into the subcutis, as well as an increase of Ki-67 positivity. Since the lesion showed repeated relapse within a short period, we performed wide-field resection of the tumor with a 3-cm margin. Currently, 48 months after surgery, there has been no local recurrence or metastasis, but continuous strict follow-up will be necessary.

(c) 2015 S. Karger AG, Basel
\end{abstract}

KARGER 125/s $\quad \begin{aligned} & \text { Kanako Tsunoda } \\ & \text { Department of Dermatology, School of Medicine } \\ & \text { Iwate Medical University } \\ & \text { Uchimaru 19-1, Morioka, Iwate 020-8505 (Japan) } \\ & \text { E-Mail ktakami0531@gmail.com }\end{aligned}$


Case Reports in
Dermatology

\begin{tabular}{l|l}
\hline \multicolumn{2}{l}{ Case Rep Dermatol 2015;7:10-16 } \\
\hline DOI: 10.1159/000371790 & $\begin{array}{l}\text { ○ 2015 S. Karger AG, Basel } \\
\text { www.karger.com/cde }\end{array}$ \\
\hline
\end{tabular}

Tsunoda et al.: A Case of Cellular Fibrous Histiocytoma on the Right Elbow with Repeated Relapse within a Short Period

\section{Introduction}

Cellular fibrous histiocytoma (CFH) is a variant of fibrous histiocytoma (FH) that was first described by Calonje et al. [1] in 1994. In contrast to ordinary FH, a striking feature of CFH is its high cellularity, limited polymorphism, a fascicular growth pattern and a partly storiform pattern [1-3]. Although generally considered a benign tumor, CFH has a tendency for local recurrence [1]. Here we report a case of CFH that showed local recurrence twice within a period of 9 months, allowing comparison of the cell morphology between the primary and recurrent tumors. We also discuss the immunohistological differences between $\mathrm{CFH}$ and dermatofibrosarcoma protuberans (DFSP).

\section{Case Presentation}

A healthy 36-year-old Japanese woman presented with a slightly painful cutaneous tumor on her right elbow. It had been present for 3 months and had gradually increased in size. The tumor was resected and the pathological diagnosis was FH. However, it recurred 3 months later and once again at 6 months, being resected on each occasion. The tumor was $2.0 \mathrm{~cm}$ in size and revealed a hard consistency (fig. 1). Because of the repeated relapse within a short period, we performed wide-field resection of the tumor with a 3-cm margin. Microscopic examination of the specimen revealed a well-defined lesion located in the dermis and extending to the subcutaneous fat (fig. 2a), exhibiting an irregular lace-like pattern between the fat cells (fig. $2 \mathrm{~b}$ ). The overlying epidermis was slightly hyperplastic with basal cell hyperpigmentation. The lesion was composed of monomorphic spindle cells with a mixed fascicular and storiform growth pattern (fig. 2c). Hemosiderin deposits and giant cells were occasionally observed. Nuclear atypia was not evident. At the periphery of the lesion, tumor cells were seen dissecting dermal collagen bundles. No necrosis was present. The mitotic count was 7 per 10 high-power fields (HPF). Immunohistochemical staining revealed positivity for vimentin, factor XIIIa, CD68, CD163 (fig. 2d) and CD44 (fig. 2e), but no reactivity for CD34 (fig. 2f), desmin, AE1/AE3 or S100 protein. Based on these findings, a diagnosis of CFH was made. We compared the cell morphology of the primary lesion (fig. 3 a) with that of the first (fig. 3b) and second (fig. 3c) recurrences. Histological examination of the primary tumor revealed irregularly arranged collagen fibers mixed with scattered proliferations of plump spindle cells. However, the recurrent lesion demonstrated an increase in cellularity, the tumor cells being monomorphic slimmer spindle cells proliferating at greater depth in the dermis. In addition, a storiform pattern was partly evident in the recurrent tumors. In order to evaluate the proliferative activity of the tumor, Ki-67 staining was performed. The primary tumor showed 2\% positivity for Ki-67 (fig. 3d), whereas the first and second recurrent tumors showed 10\% (fig. 3e) and 7\% (fig. 3f) positivity. At 48 months of follow-up, the patient had no evidence of further local recurrence or metastasis.

\section{Discussion}

Histologically, CFH shows high cellularity and is composed of spindle-shaped cells with variable amounts of eosinophilic cytoplasm and small, oval, vesicular eosinophilic nuclei. Most CFHs occupy the superficial dermis and extend into the deep reticular dermis, showing focal extension into subcutaneous fat, fascicular proliferative growth, and partly storiform architecture with little or no collagen architecture between the cells. Invasion of the subcu- 
Tsunoda et al.: A Case of Cellular Fibrous Histiocytoma on the Right Elbow with Repeated Relapse within a Short Period

taneous fat is always superficial and characterized by an irregular lace-like pattern between the fat cells. Epidermal changes range from mild to prominent acanthosis, and basal cell hyperpigmentation is not evident. At the periphery of the lesion, somewhat hyalinized collagen bundles may be surrounded by tumor cells. Cytologic atypia is not a feature, and the mean mitotic count is 3 per $10 \mathrm{HPF}$. Inflammatory cells are focally present, comprising lymphocytes, plasma cells, foamy macrophages and, less commonly, giant cells [1-3].

The distinction between CFH and DFSP can be diagnostically problematic, especially in cases of CFH with significant cellularity, a storiform arrangement of the tumor cells and extensive involvement of the subcutaneous tissue. Traditionally, CD34 and factor XIIIa have been widely used to distinguish CFH from DFSP [4-6]. However, there is a degree of immunohistochemical phenotypic overlap between CFH and DFSP. For instance, some degree of CD34 expression has been observed in up to $20 \%$ of dermatofibromas and dermatofibroma variants, while scattered factor XIIIa expression has also been documented in $20 \%$ of DFSP [5-8]. For this reason, a more reliable marker for the differential diagnosis of CFH from DFSP is needed. Recent studies have shown that CD163 and CD44 are specific for FH and its variants. CD163, a hemoglobin scavenger receptor expressed in monocytes and tissue macrophages, is reportedly expressed in $\mathrm{FH}(89 \%)$ and $\mathrm{CFH}(100 \%)$, whereas it is negative in DFSP (83\%) [9]. In addition, CD44 is the cell surface receptor for hyaluronate and has also been reported to be a useful diagnostic marker of CFH [10]. These results support the possibility that CD163 and CD44 may be useful for distinguishing CFH from DFSP. A combination of these markers could to be more reliable for distinction between the two entities. In addition, histologically, the differential diagnosis of CFH includes atypical FH (AFH), a FH variant. Although it is known that many cases of AFH follow a benign course, the rate of local recurrence is $14 \%$, mostly involving cases where resection has been incomplete. The distinctive histological features of AFH include a dermal lesion extending into superficial subcutaneous adipose tissue, composed of a population of pleomorphic spindled cells with large, irregular and hyperchromatic nuclei admixed with multinucleated giant cells, and macrophages as well as hemosiderin deposits [11]. Since in the present case the tumor cells lacked cellular pleomorphism and nuclear atypia, AFH was excluded.

Although CFH is considered to be a benign tumor, rare cases of metastasis have been reported. According to Colome-Grimmer and Evans [12], who described two cases of metastasizing $\mathrm{CFH}$, patient 1 suffered recurrence three times (17, 26 and 29 months after resection) and metastasis to the inguinal lymph nodes and lung, whereas patient 2 suffered a single recurrence ( 3 months after resection) and metastasis to the right cervical lymph nodes. Doyle and Fletcher [13] described 16 cases of metastasizing FH, among which 11 were CFH, and 7 patients suffered local recurrence; 2 patients suffered 3 recurrences and 1 patient suffered 7 recurrences. The risk factors for metastasis may include large tumor size, high cellularity, local recurrence and aggressive behavior $[12,13]$. We consider that the present case was aggressive because recurrence was observed twice within a short period and the recurrent tumors showed increased cellularity and mitotic activity in comparison with the primary tumor. 48 months after surgery, there has been no further local recurrence or metastasis, but a continuous strict follow-up will be necessary.

The recurrence rate for ordinary FH, even when incompletely excised, is $<2 \%$ [14], whereas for cellular variants the recurrence rate is $26 \%$ [1]. CFH of the skin is considered to be benign, but rare cases showing multiple recurrences and involving metastasis to the lymph nodes and internal organs have been reported $[12,13]$. Therefore an adequate resection margin and close clinical follow-up are mandatory. 


\section{Case Reports in Dermatology}

\begin{tabular}{l|l}
\hline \multicolumn{2}{l}{ Case Rep Dermatol 2015;7:10-16 } \\
\hline DOI: $10.1159 / 000371790$ & $\begin{array}{l}\text { C } 2015 \text { S. Karger AG, Basel } \\
\text { www.karger.com/cde }\end{array}$ \\
\hline
\end{tabular}

Tsunoda et al.: A Case of Cellular Fibrous Histiocytoma on the Right Elbow with Repeated Relapse within a Short Period

\section{Disclosure Statement}

The authors have no conflicts of interest to disclose.

\section{References}

1 Calonje E, Mentzel T, Fletcher CD: Cellular benign fibrous histiocytoma. Clinicopathological analysis of 74 cases of a distinctive variant of cutaneous fibrous histiocytoma with frequent recurrence. Am J Surg Pathol 1994;18:668-676.

2 Elder D (ed): Lever's Histopathology of the Skin, ed 9. Philadelphia, Lippincott Williams and Wilkins, 2005.

-3 Franquemont DW, Cooper PH, Shmookler BM, Wick MR: Benign fibrous histiocytoma of the skin with potential for local recurrence: a tumor to be distinguished from dermatofibroma. Mod Pathol 1990;3:158163.

4 Aiba S, Tabata N, Ishii H, Ootani H, Tagami H: Dermatofibrosarcoma protuberans is a unique fibrohistiocytic tumour expressing CD34. Br J Dermatol 1992;127:79-84.

5 Altman DA, Nickoloff BJ, Fivenson DP: Differential expression of factor XIIIa and CD34 in cutaneous mesenchymal tumors. J Cutan Pathol 1993;20:154-158.

-6 Abenoza P, Lillemoe T: CD34 and factor XIIIa in the differential diagnosis of dermatofibroma and dermatofibrosarcoma protuberans. Am J Dermatopathol 1993;15:429-434.

-7 Zelger B, Sidoroff A, Stanzl U, Fritsch PO, Ofner D, Zelger B, Jasani B, Schmid KW: Deep penetrating dermatofibroma versus dermatofibrosarcoma protuberans. A clinicopathologic comparison. Am J Surg Pathol 1994;18:677-686.

8 Kahn HJ, Fekete E, From L: Tenascin differentiates dermatofibroma from dermatofibrosarcoma protuberans: comparison with CD34 and factor XIIIa. Hum Pathol 2001;32:50-56.

-9 Sachdev R, Sundram U: Expression of CD163 in dermatofibroma, cellular fibrous histiocytoma, and dermatofibrosarcoma protuberans: comparison with CD68, CD34, and factor XIIIa. J Cutan Pathol 2006;33:353-360.

10 Calikoglu E, Augsburger E, Chavaz P, Saurat JH, Kaya G: CD44 and hyaluronate in the differential diagnosis of dermatofibroma and dermatofibrosarcoma protuberans. J Cutan Pathol 2003;30:185-189.

$\checkmark 11$ Kaddu S, McMenamin ME, Fletcher CD: Atypical fibrous histiocytoma of the skin: clinicopathologic analysis of 59 cases with evidence of infrequent metastasis. Am J Surg Pathol 2002;26:35-46.

$\$ 12$ Colome-Grimmer MI, Evans HL: Metastasizing cellular dermatofibroma. A report of two cases. Am J Surg Pathol 1996;20:1361-1367.

13 Doyle LA, Fletcher CD: Metastasizing 'benign' cutaneous fibrous histiocytoma: a clinicopathologic analysis of 16 cases. Am J Surg Pathol 2013;37:484-495.

14 Fletcher CDM, Calonje E: Cutaneous fibrohistiocytic tumors: an update. Adv Anat Pathol 1994;1:2-15. 
Tsunoda et al.: A Case of Cellular Fibrous Histiocytoma on the Right Elbow with Repeated Relapse within a Short Period

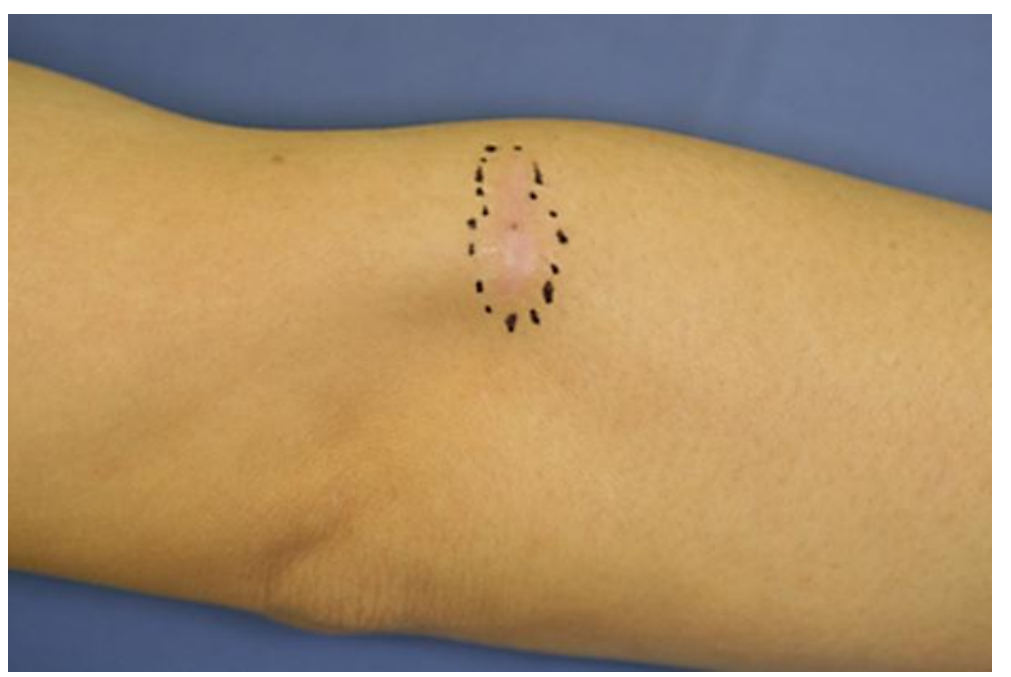

Fig. 1. Macroscopic view of the 2.0 -cm subcutaneous tumor on the right elbow. 


\section{Case Reports in Dermatology}

\begin{tabular}{l|l}
\hline Case Rep Dermatol 2015;7:10-16 \\
\hline DOI: 10.1159/000371790 & $\begin{array}{l}\text { @ 2015 S. Karger AG, Basel } \\
\text { www.karger.com/cde }\end{array}$ \\
\hline
\end{tabular}

Tsunoda et al.: A Case of Cellular Fibrous Histiocytoma on the Right Elbow with Repeated Relapse within a Short Period
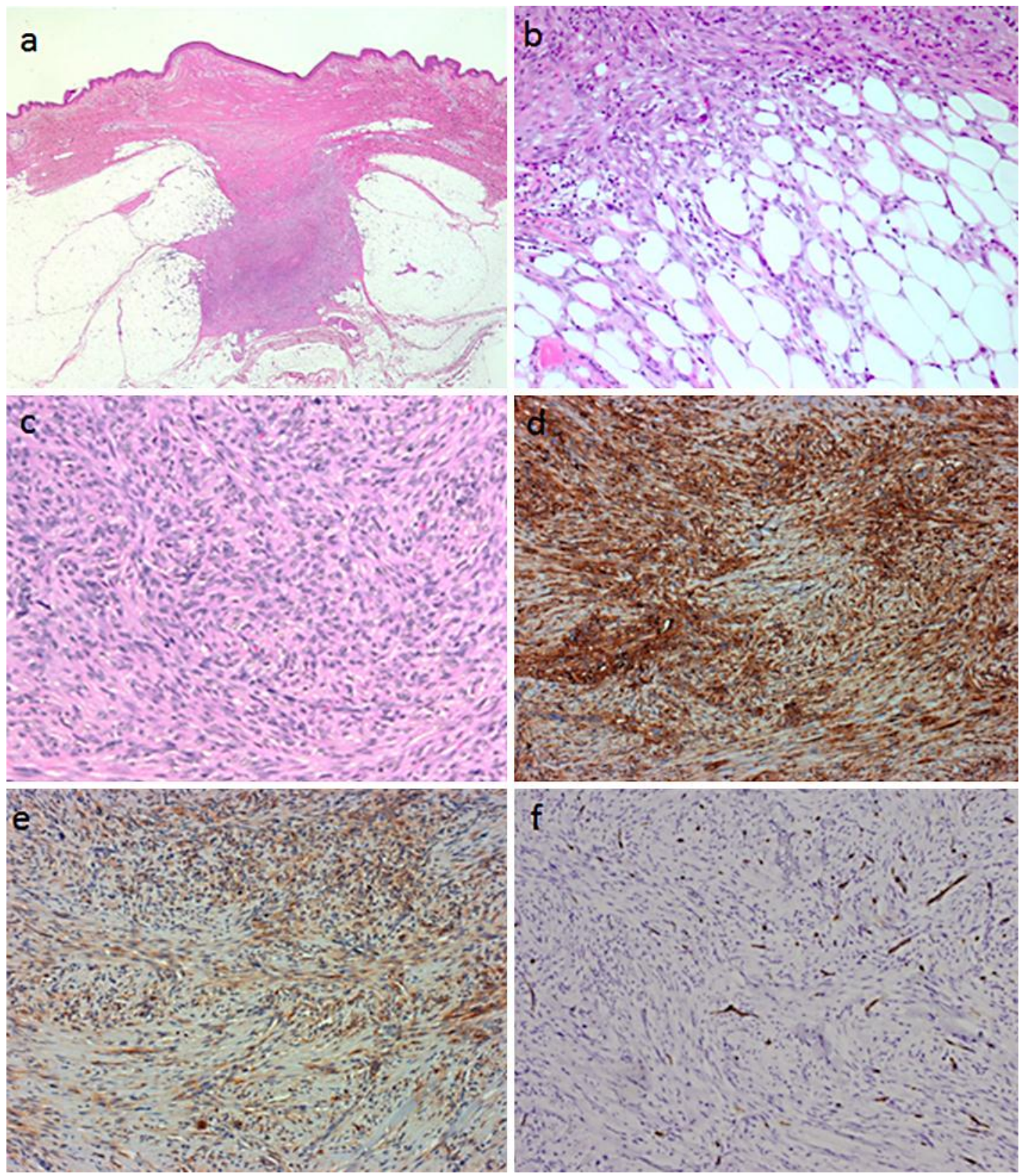

Fig. 2. Histological appearance of the lesion. a Dermal-to-subcutaneous tumor with extension into the subcutaneous tissue. The epidermis appeared hyperplastic $(\mathrm{HE}, \times 1)$. $\mathbf{b}$ The tumor extended into subcutaneous fat with an irregular lace-like pattern (HE, $\times 400)$. c Tumor cells appeared spindle-shaped and monomorphic and had a mixed fascicular and storiform growth pattern (HE, $\times 400$ ). $\mathbf{d}-\mathbf{f}$ Immunohistochemistry of the tumor cells. The cells were positive for CD163 (d) and CD44 (e), but negative for CD34 (f). 


\section{Case Reports in Dermatology}

\begin{tabular}{l|l}
\hline \multicolumn{2}{l}{ Case Rep Dermatol 2015;7:10-16 } \\
\hline DOI: $10.1159 / 000371790$ & $\begin{array}{l}\text { C } 2015 \text { S. Karger AG, Basel } \\
\text { www.karger.com/cde }\end{array}$ \\
\hline
\end{tabular}

Tsunoda et al.: A Case of Cellular Fibrous Histiocytoma on the Right Elbow with Repeated Relapse within a Short Period
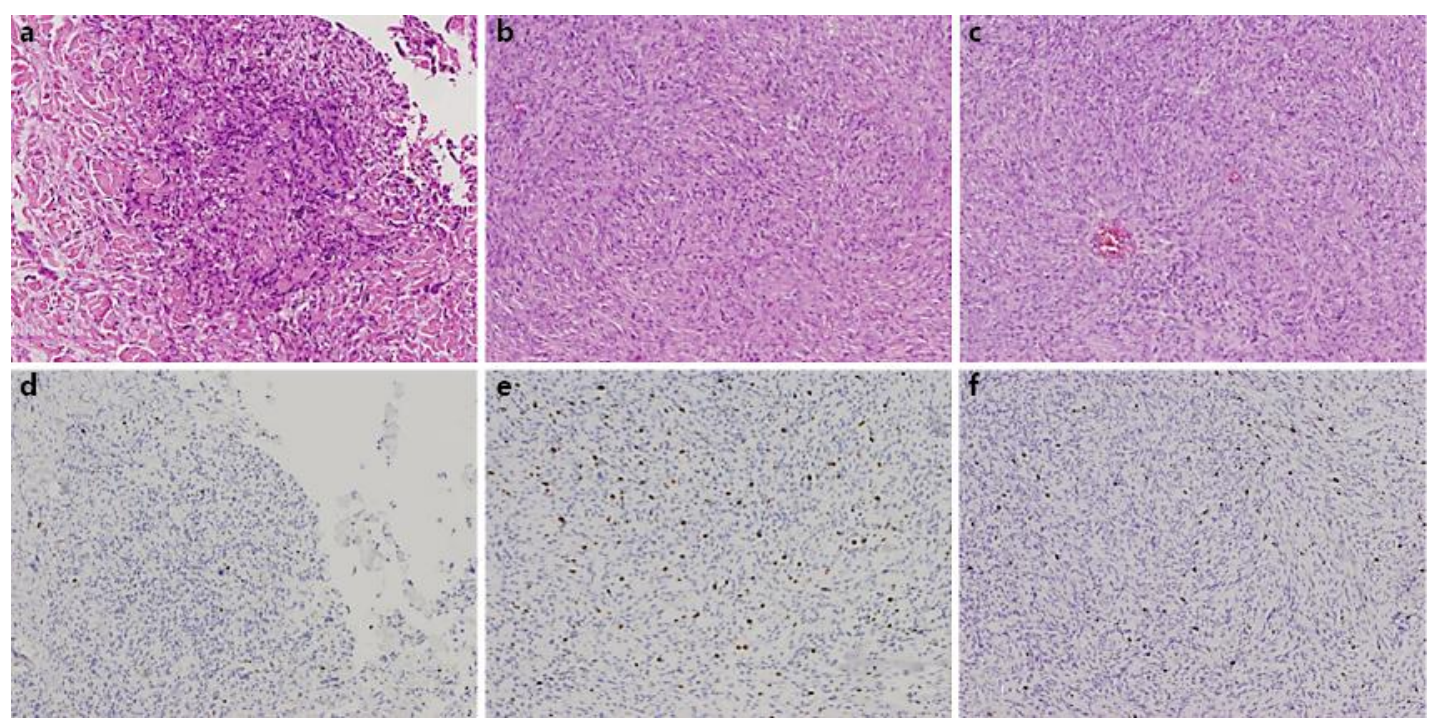

Fig. 3. a-c Cell morphology of the primary and recurrent tumors. a The primary tumor showed irregularly arranged collagen fibers mixed with scattered proliferating fibroblast. $\mathbf{b}$ The first recurrent tumor, composed of slimmer spindle cells. $\mathbf{c}$ The second recurrent tumor, composed of slimmer spindle cells. Cells in the recurrent tumors were more monomorphic and showed higher cellularity. $\mathbf{d}-\mathbf{f}$ Immunostaining for Ki-67. The Ki-67 labeling index of the primary tumor was $2 \%$ (d) and that of the first and second recurrent tumors $10 \%$ (e) and $7 \%$ (f), respectively. 